\title{
Towards Sustainable Phenolic Thermosets with High thermal Performances
}

Lérys Granado, ${ }^{a}$ Romain Tavernier, ${ }^{a}$ Ségolène Henry, ${ }^{a}$ Ruth Oye Auke, ${ }^{a}$ Gabriel Foyer, ${ }^{b}$ Ghislain David ${ }^{a}$ and Sylvain Caillol ${ }^{\mathrm{a} *}$

${ }^{a}$ Institut Charles Gerhardt UMR-5253, CNRS, Université de Montpellier, ENSCM, 40, Avenue Professeur Emile Jeanbrau, 34296 Montpellier, France

${ }^{b}$ ArianeGroup, Rue de Touban, 33185 Le Haillan, France.

*Corresponding author: sylvain.caillol@enscm.fr

Supporting Information: Viscosities, NMR, Mass and IR spectra of Prepolymers, Curing Kinetics Computations, Curing Schemes, Solid and Insoluble contents, and Sample Photography

\section{Abstract}

This paper proposes more sustainable alternatives for the synthesis of high thermal performances phenolic networks. Terephthalaldehyde (TPA), a non-toxic aromatic dialdehyde, was selected to replace formaldehyde. Phenol was in turns replaced with bio-based and non-toxic phenolic building blocks: resorcinol as model for tannins, guaiacol which is easily accessible from lignin and tyrosol from olive oil mill wastewaters. The prepolymerization was performed under mild conditions (ethanol, $\mathrm{T} \leq 100^{\circ} \mathrm{C}$ ). The liquid prepolymers were characterized by NMR, IR, MALDI-ToF and rheology. The curing behavior of these formulations was assessed by DSC and IR spectroscopy. An advanced isoconversional analysis of the DSC data allowed the determination of crosslinking activation energies. Furthermore, a multiple-step mechanism of TPA crosslinking was proposed with strong evidences. The thermo-mechanical properties of cured networks were characterized using DMA, showing high crosslink densities and fairly elevated glass transition temperatures. Finally, it has been proven that these new thermosets display very high thermal performances under pyrolysis conditions (TGA).

TOC

New sustainable high-performance phenolic thermosets are synthesized from non-toxic and potentially biobased chemicals. We report understanding of curing mechanism and outstanding performances of networks.

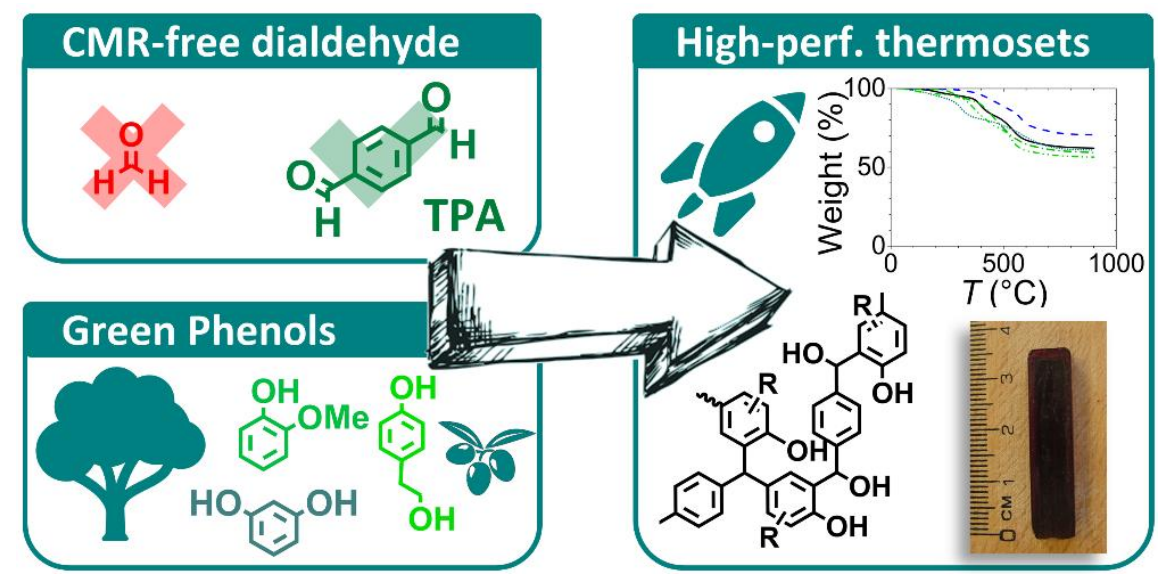

\section{Key-words}

Thermal stability; thermosets; terephthalaldehyde; phenol; resorcinol; guaiacol; tyrosol;

\section{Introduction}

Phenol-formaldehyde (PF) polymers were the first synthetic thermosetting plastics produced at industrial scale, in the early $20^{\text {th }}$ century. ${ }^{1}$ More than one hundred years later, phenolic thermosets continue to be widely used with a production of more than 6 million tons per year worldwide. ${ }^{2}$ Phenolic thermosets are highly crosslinked networks, presenting very high thermal performances ${ }^{3}$, hardly overtaken by other organic polymers. ${ }^{4,5}$ Such high thermal performances are mainly due to their very high aromatic and crosslink densities. ${ }^{6}$ Their elevated degradation temperatures and high char yields make phenolic thermosets key materials for aerospace applications. ${ }^{7}$ 
However, PF present several disadvantages that still need to be addressed. First, phenol and formaldehyde are hazardous substances, classified as carcinogenic, mutagenic and reprotoxic (CMR) substances by the European Chemical Agency $(E C H A)^{8}$. Moreover, phenol and formaldehyde are oil-based building blocks which are subject to petroleum price volatility. Furthermore, PF are thermosetting polymers consisting in a three-dimensional network which make them insoluble and infusible, preventing any recycling strategy. Thus, efforts focus on finding alternative strategies to replace both phenol and formaldehyde, in order to develop more sustainable high thermal performance resins. The replacement of formaldehyde is the main challenge. For the sake of high performances, a potential substituent of formaldehyde must display a good reactivity and a low molecular weight to achieve very high crosslink and aromatic densities. Hence, phenolic networks with aliphatic aldehydes do not present the required thermal resistance. ${ }^{9}$ Previous authors replaced formaldehyde by various aliphatic aldehydes such as glyoxal ${ }^{10}$ and furfural. ${ }^{11,12}$ However, those bio-based building blocks are also classified CMR by the ECHA ${ }^{8}$.

We have previously reported the replacement of formaldehyde by bio-based and non-toxic aromatic dialdehydes ${ }^{13}$, which were reacted with phenol in alkaline conditions (resoles). Among them, terephthalaldehyde (TPA) showed the best reactivity. The second aldehyde group in para position of the first one, acts as an electron-withdrawing group, consequently enhancing the reactivity of its counterpart. TPA can react four times with phenols (addition and condensation reactions on both aldehyde moieties), yielding highly crosslinked and aromatically dense structures. Furthermore, TPA is non-toxic and is considered as a potentially bio-based substance ${ }^{14}$, as it can be obtained via gasphase oxidation of biosourced para-xylene (key building block for production of polyethylene terephthalate) ${ }^{15,16}$ Paraxylene can be obtained by catalytic pyrolysis or hydrocracking of lignin, ${ }^{17}$ successive processes using fermentation of feedstock by microorganisms, ${ }^{18}$ Diels-Alder reaction, ${ }^{19}$ and several other pathways. ${ }^{20}$ We have deeply studied the curing behavior of phenol-terephthalaldehyde resoles. ${ }^{21}$ Overall, we demonstrated that these new thermosets can effectively replace phenol-formaldehyde, exhibiting comparable curing behavior with higher thermal performances than PF.

On the other hand, phenol still has to be replaced by non-toxic substances in resole formulations. Phenolic building blocks must present a high aromatic content and an enhanced reactivity with enough activated positions (i.e. nucleophilic) to achieve suitable crosslinked networks. Phenolic building blocks can be readily provided from biomass such as lignin, tannins and plant oils. ${ }^{22}$ Lignin is a natural polymer found in plant cell walls which stands as one significant source of bio-based phenolic compounds. ${ }^{22-25}$. The lignin is mainly produced from paper and pulp industry wastes, with a global production estimated at 50 million of tons per year. ${ }^{26}$ Lignin depolymerization strategies using green chemistry principles seems very promising to produce aromatic building blocks. Basically, three basic units compose the lignin: $p$ hydroxyphenyl, guaiacyl and syringyl. ${ }^{27}$ Polymers, and especially phenolic networks, can be synthesized from either treated or depolymerized lignins, which are used either as additives or as crosslinkers. ${ }^{28-31}$ 32,33 Moreover, guaiacol which can be extracted from lignin pyrolysis ${ }^{36,37}$ is a candidate of prime-choice for phenolic thermosets synthesis, presenting several advantages such as biocompatibility, ${ }^{35}$ aromatic structure with a low molecular mass and reactivity towards aldehyde with two reactive positions (para and meta). ${ }^{34}$ Previous studies report that guaiacol was successfully reacted with formaldehyde ${ }^{38,39}$ and involved in other polymers. ${ }^{34,40}$ Yet, to the best of our knowledge, no study has reported the reaction with aromatic dialdehydes.

Moreover, phenolic structures can be also provided from tannins ${ }^{41}$ which are polyphenolic molecules found in all kinds of plant. There are two categories of tannins: hydrolysable and condensed tannins. Especially, condensed tannins have raised numerous interests as bio-based phenolic sources with their flavonoid units. ${ }^{41}$ Condensed tannins were often used directly as phenolic substituents, especially in wood adhesive applications. ${ }^{22,42}$ In addition, resorcinol was already widely used in phenolic formulations. ${ }^{43-45}$ Resorcinol is of great interest because of its enhanced reactivity (due to 2 ortho-para positions which are nucleophilic). The ortho-ortho position is expected to be less reactive than orthopara one due to the steric hindrance. ${ }^{46}$ Biosourced resorcinol can be obtained via different routes. ${ }^{47,48}$ Moreover, resorcinol displays a more balanced reactivity than phloroglucinol and pyrogallol (whose pot-lifes are expected to be very short in resole formulations). Additionally, resorcinol is less toxic than catechol and pyrogallol that are both suspected to be CMR substances ${ }^{8}$. Consequently, resorcinol was chosen as a bio-based model simulating condensed tannins in our formulations. 
Furthermore, non-toxic phenolic monomers can be readily found in plant oils. Among them, tyrosol has aroused our attention. It is one of the main antioxidants found in olive and argan oils. ${ }^{49}$ This natural phenol is used in cosmetics, pharmaceutical ${ }^{50}$ and food preservative ${ }^{51}$ applications. The olive oil production in European Union is over 2 million of tons per year and $8 \mathrm{~m}^{3}$ of olive mill wastewater is produced per ton of olive oil, ${ }^{52}$ resulting in a potential tyrosol production reaching up to hundreds of tons per year, in Europe. ${ }^{53}$ Hence ongoing research evaluates extraction strategies from olive mill wastewater. ${ }^{53,54}$ In addition, tyrosol is accessible from other renewable feedstocks, such as sugars via enzymatic reactions. ${ }^{55}$ Tyrosol presents a low molecular mass and has two reactive positions (ortho). It has been recently and successfully used as a flame-retardant precursor, ${ }^{56}$ thanks to its free radical scavenging properties. Thus, tyrosol stands as one bio-based phenol of prime-choice for high thermal performance resole synthesis.

In the present investigation, we aim to demonstrate - as a proof-of-concept - that phenolic thermosets can be obtained from potentially bio-based and non-toxic building blocks, without any loss of thermal and mechanical properties. Resorcinol, guaiacol and tyrosol are reacted with terephthalaldehyde. Furthermore, quantitative data are provided on crosslinking kinetics, giving insights in reaction mechanisms, thermo-mechanical properties and thermal resistance. Finally these biobased phenolic thermosets and are compared to a commercial PF and phenol-TPA, as systems of reference (Scheme 1). Hence, this paper aims to give a balance between insights in mechanistic elucidations and key features for further developments of these new phenolic thermosets.
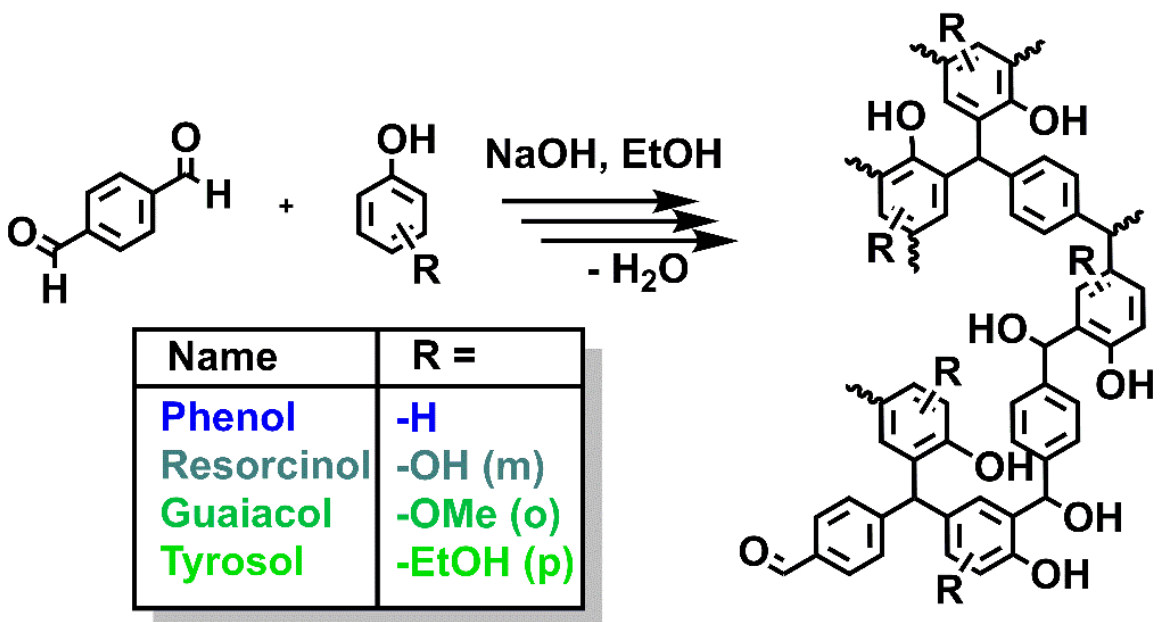

Scheme 1: Reaction between terephthalaldehyde (TPA) and the different green phenols of this study.

\section{Experimental Section}

\section{Materials}

The absolute ethanol was purchased from VWR. The phenol (P) was purchased from Alfa-Aesar. The terephthalaldehyde (TPA), the resorcinol (R) and tyrosol (T) were purchased from TCl Chemicals. The guaiacol (G), 2,4,6-trimethylphenol and the sodium hydroxide were purchased from Sigma-Aldrich. Aqueous $\mathrm{NaOH}$ (50 wt.\%) solution was prepared using milli-Q (Millipore) water. Phenol-formaldehyde (PF) was a commercial liquid prepolymer resole, containing methanol and sodium hydroxide. Deuterated dimethylsulfoxide (DMSO-d6) was purchased from Eurisotop. All chemicals were 98-99\% pure and used without further purification. Prepolymers were stored at $-18{ }^{\circ} \mathrm{C}$ to prevent unwanted reactions.

\section{Prepolymer syntheses}

An excess of phenolic building block (i.e. $\mathbf{P}, \mathbf{R}, \mathbf{G}$ or $\mathbf{T}$ ) and absolute ethanol (regarding final formulation: $\leq 20 \mathrm{wt} . \%$ for $\mathbf{P}$ and $\mathbf{G}$, and $\leq 50 \mathrm{wt}$.\% for $\mathbf{R}$ and $\mathbf{T}$ for solubility issues) were poured in a two-necked round-bottom flask equipped with a condenser, a magnetic stirrer and placed in a heated silicone oil bath (regulated at $\pm 0.1{ }^{\circ} \mathrm{C}$ ), at $100{ }^{\circ} \mathrm{C}$ for $\mathbf{P}, \mathbf{G}$ and $\mathbf{T}$, and $30{ }^{\circ} \mathbf{C}$ for $\mathbf{R}$ (lower temperature due to the elevated reactivity of $\mathbf{R}$ ). Once the mixture was liquid and homogenous, TPA was added, the color passed from transparent to orange. After 5 min of homogenization, 0.04 equivalent of $\mathrm{NaOH}(50$ wt.\% aqueous solution) were poured in the flask, the color became brownish. The reaction was kept until $95 \%$ 
conversion of the first aldehyde moiety of TPA, i.e. approximately $4 \mathrm{~h}$ for $\mathbf{P}, 1.75 \mathrm{~h}$ for $\mathbf{R}, 4 \mathrm{~h}$ for $\mathbf{G}$ and $14 \mathrm{~h}$ for $\mathbf{T}$. Samples were regularly taken off to follow the reaction by ${ }^{1} \mathrm{H}$ NMR. Afterward the mixture was quenched in an ice bath. In the end, the mixtures were homogeneous, moderately viscous and were dark-violet for $\mathbf{P}$, light-orange for $\mathbf{R}$, darkgreen for $\mathbf{G}$ and dark-orange for $\mathbf{T}$. The pre-polymers were used as prepared and studied without any purification.

\section{Characterization techniques}

The prepolymer viscosities were measured at $25^{\circ} \mathrm{C}$ on the AR-1000 rheometer (TA instrument). A 25 mm diameter and $4^{\circ}$ cone-plan geometry were used. The flow mode was used with a gradient from 700 to $10 \mathrm{~s}^{-1}$. The viscosity value is the average value over 10 points (Fig. S1 of the Supporting Information).

${ }^{1} \mathrm{H}$ and ${ }^{13} \mathrm{C}$ nuclear magnetic resonance (NMR) spectra were recorded on a Bruker AC 400 instrument, using deuterated dimethylsulfoxide-d6 as solvent.

The matrix-assisted laser desorption/ionization time of flight mass (MALDI-ToF) spectrometry experiments were performed on a Bruker Rapiflex MALDI-ToF instrument. Measurements have been recorded in positive reflectron mode, using the following conditions: positive voltage polarity, with a pulsed ion extraction delay of 170 ns with 4000-6000 shots per analysis. The matrix used was 2,5-dihydroxybenzoic acid. $\mathrm{LiCl}$ was used as a cationising agent. Matrix, samples and cationising agent were mixed with 10/1/1 proportions and dissolved in acetone with a $10 \mathrm{mg} / \mathrm{mL}$ concentration. $1 \mu \mathrm{L}$ of this solution was placed on the MALDI target and the target was allowed to dry in ambient conditions. A peptide mixture has been used for calibration.

Attenuated total reflectance Fourier transform infrared absorption spectroscopy (ATR-FTIR) measurements were carried out on a Nicolet 6700 spectrometer from Thermo-Scientific, equipped with a mercury-cadmium-tellurium detector, in the middle infrared range with a resolution of $4 \mathrm{~cm}^{-1}$ and 32 scans were coadded to each spectrum.

Differential scanning calorimetry (DSC) was used to study the resole curing processes. The apparatus was the DSC-3 F200 Maia (Netzsch $\mathrm{GmbH}$ ) equipped with an intra-cooler module. The atmosphere was dry nitrogen at a flow rate of 50 $\mathrm{mL} \cdot \mathrm{min}^{-1}$. The temperature sensor was freshly calibrated with biphenyl, indium, bismuth and $\mathrm{CsCl}$ standards at 10 ${ }^{\circ} \mathrm{C} \cdot \mathrm{min}^{-1}$. High-pressure stainless-steel pans and lids (100 MPa, sealed at $3 \mathrm{~N} \cdot \mathrm{cm}$ ) were used to prevent unwanted signal from volatile evaporation. The prepolymer samples were inserted with a syringe into the pan and weighed on a $0.01 \mathrm{mg}$ precise analytical balance. No leak was recorded, as the pans were weighed again after analysis. To carry out the kinetics study, the heating rates were selected around the calibration: $\beta=5,7.5,10,12.5$ and $15^{\circ} \mathrm{C} \cdot \mathrm{min}^{-1}$.

Dynamic mechanical analysis (DMA) was carried out on a DMA 25 apparatus (Metravib, Acoem) in tensile mode, under controlled atmosphere (pulsed air). The imposed dynamic displacement was $50 \mu \mathrm{m}$, which corresponds to less than $0.2 \%$ strain (within linear domain), without any static auto-tension. The cyclic solicitation was imposed at $1 \mathrm{~Hz}$. The samples dimensions were ca. $35.0 \times 10.0 \times 3.0 \mathrm{~mm}^{3}$. The samples were fully cured with the slow curing program and were probed from $\mathrm{RT}$ to $250{ }^{\circ} \mathrm{C}$ at $5^{\circ} \mathrm{C} \cdot \mathrm{min}^{-1}$.

Thermogravimetric analysis (TGA) was performed on a TGA-3 libra (Netzsch). Between 10 and 12 mg of monolithic samples were weighed in open alumina pans. The atmosphere was dried nitrogen at $40 \mathrm{~mL} / \mathrm{min}$. The heating rates were $5{ }^{\circ} \mathrm{C} \cdot \mathrm{min}^{-1}$ to follow the curing and $10^{\circ} \mathrm{C} \cdot \mathrm{min}^{-1}$ to monitor the thermal performances of cured resins (fast curing program), from $\mathrm{RT}$ to $900{ }^{\circ} \mathrm{C}$, followed by an isothermal step of $1 \mathrm{~h}$, at $900{ }^{\circ} \mathrm{C}$, to be sure that the char residues were stable.

\section{Results and Discussion}

\section{Prepolymer characterization}

The oligomer structures obtained after prepolymerization were firstly elucidated using NMR (Fig. S2-S7). Similarly to phenol-formaldehyde addition reaction, the addition (i.e. electrophilic aromatic substitution) between phenol and TPA yielded alcohol moieties. However, in the case of TPA-based resoles, secondary alcohols are created 
(methylenol bridges between two aromatic rings), as evidenced by NMR spectra. Based on literature data of model compounds, ${ }^{57,58}$ we were also able to discriminate the ortho and para (less deshielded) substituted positions in phenolTPA. The same amount of ortho and para substituted positions was found. Furthermore, triphenylmethane were detected as the results of the condensation of methylenol with phenol (TPA-phenol formulation), in accordance with a recent study ${ }^{59}$. For the other bio-based phenols, such precise attribution was more challenging and required comparison to model molecules.

Additionally, MALDI-ToF allowed to determine the distribution of oligomer masses (Fig. S8), in accordance with the literature. ${ }^{60}$ Overall, the oligomers have low molecular weights $\left(M_{w}<2,000 \mathrm{~g} \cdot \mathrm{mol}^{-1}\right)$. Tyrosol-TPA is the formulation that exhibits the lowest molecular weights, $M_{w}$ ranging from ca. 400 to $700 \mathrm{~g} \cdot \mathrm{mol}^{-1}$, whereas the most reactive resorcinol-TPA shows the highest $M_{w}$ values (up to ca. $1,900 \mathrm{~g} \cdot \mathrm{mol}^{-1}$ ). The mass difference between the oligomers can readily provide insights into the polymerization mechanisms. Based on these data, oligomer structures are proposed in Tables S1-S4. Basically, three repeating mass differences are noticed: (i) addition involving TPA, (ii) addition of the phenol onto a dangling aldehyde moiety of oligomer and (iii) the condensation of the phenol onto the methylenol group, with release of water. For all formulations, it is noteworthy that most of the reactions involving the addition of a phenolic ring on the oligomers are condensation reactions. Therefore the second aldehyde is found to remain mostly unreacted (in agreement with NMR and IR spectroscopies).

\section{Crosslinking mechanisms}

Resoles are thermally curable polymers which do not need further addition of curing agent for crosslinking. DSC was performed to investigate the curing behavior of the synthesized resoles. Exothermic peaks, typical of thermoset crosslinking reactions, are shown in the non-isothermal thermograms (Fig. 1). One single peak is observed for PF, which is mainly assigned to the polycondensation reaction of phenol with methylol groups. In contrast, multiple reactions are observed for TPA resoles ( 2 for phenol, resorcinol and guaiacol and 3 for tyrosol). The shift from one reaction to another occurs at the same crosslinking degree regardless of the heating rates - as shown in the kinetic profiles in Fig. S9. Therefore, the multiple reactions are considered consecutive rather than competitive.

The total enthalpy of crosslinking values, $\Delta H_{\text {Total }}$ are reported in Table S5. The total enthalpy values span over a wide range, from 47 to $359 \mathrm{~J} \cdot \mathrm{g}^{-1}$. PF curing is the highest exothermic process. To compare the total enthalpies, average values are corrected considering the ethanol content within formulations ( $\leq 20 \mathrm{wt}$. $\%$ for phenol- and guaiacol- and $\leq 50$ wt.\% for resorcinol- and tyrosol-TPA, unknown for PF). The corrected values are comparable for phenol-, resorcinol- and guaiacol-TPA (around $240 \mathrm{~J} \cdot \mathrm{g}^{-1}$ which represents ca. $45 \mathrm{~kJ}$ per eq. phenol).

The reactivity of the formulations can be ranged by comparison of the peak maxima of exothermic signals. PF and phenol-TPA first reactions occur at similar temperatures, 167 and $163{ }^{\circ} \mathrm{C}$, respectively. Remarkably, the condensation of methylenol into phenol-TPA occurs at temperature similar to the condensation of methylol in PF. The most reactive formulation is resorcinol-TPA (first peak maximum at $107^{\circ} \mathrm{C}$ ), which contrasts with the lowest reactive formulations guaiacol- and tyrosol-TPA (first peak maxima of 186 and $181{ }^{\circ} \mathrm{C}$, respectively). For resorcinol, the presence of one second phenoxide moiety (which is being deprotonated and acting as a $+\mathrm{M}$ electron-donor) activates the aromatic ring at the same position as the first phenoxide. With this synergetic effect, the reactivity of resorcinol is found to be seriously enhanced. For guaiacol, the methoxy in ortho position of phenoxide, acts as well as $+\mathrm{M}$ electron-donor but it activates meta positions of this phenol which differs from ortho/para activating phenoxide. Hence, methoxy group occupies one reactive ortho position on the ring and creates steric hindrance. Thus, the reactivity of guaiacol is found to be reduced compared to phenol. Similarly, for tyrosol, the dangling ethanol moiety in para position of phenol occupies one potential reactive position and creates steric hindrance. In fact, the reactivity of tyrosol has been reduced. 


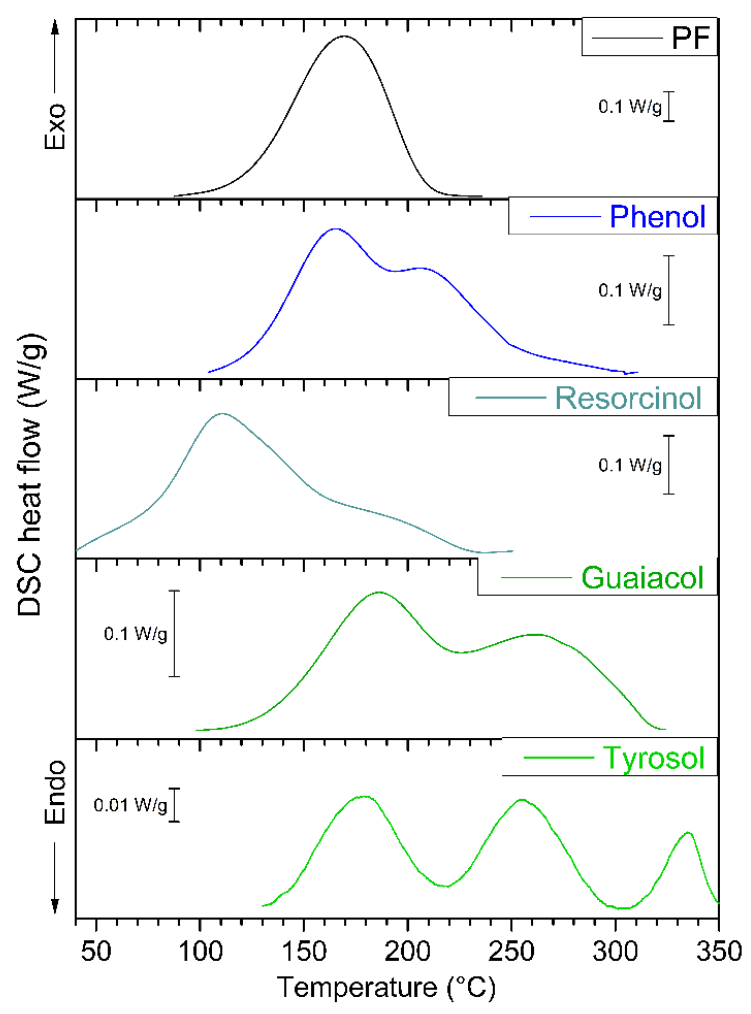

Fig. 1: DSC thermograms recorded during the pre-polymers curing, at $5 \mathrm{~K} \cdot \mathrm{min}^{-1}$.

To elucidate the undergoing mechanisms during nonisothermal curing, phenol-TPA reaction was monitored by DSC at $5{ }^{\circ} \mathrm{C} \cdot \mathrm{min}^{-1}$ until certain crosslinking degrees and rapidly quenched (Fig. S10A). The partially cured samples were analyzed by IR and NMR spectroscopies. Fig. 2 compares the spectroscopic signals of aldehydes (IR band at $1683 \mathrm{~cm}^{-1}$, $\mathrm{vC}=\mathrm{O}$, Fig. S1OB) and methylenols $\left({ }^{1} \mathrm{H} N M R\right.$, para at $5.7 \mathrm{ppm}$ and ortho at $\left.6.1 \mathrm{ppm}\right)$ to the reaction rate recorded in DSC at $5{ }^{\circ} \mathrm{C} \cdot \mathrm{min}^{-1}$. The spectroscopic results evidence that no aldehyde is involved during the first DSC reaction between phenol and TPA, and that methylenols reacted. Moreover, curing monitoring by TGA at $5{ }^{\circ} \mathrm{C} \cdot \mathrm{min}^{-1}$ shows weight losses that are concomitant with the first DSC enthalpy peak (Fig. S10C). These weight losses are ascribed to water release. Therefore, the first reaction is assigned to the condensation of phenol onto methylenol in phenol-TPA (reaction I in Scheme 2). Even though hydroxyl is a poor leaving group, previous studies showed that methide quinones are intermediates in condensation reactions. ${ }^{57,58,61-66}$ The intermediates proposed in scheme 3 would be stabilized by many resonance forms, on both sides of the carbocation. Both TPA and phenoxide groups are involved in such resonance forms and the methide quinone intermediate should be formed on the phenoxide side. IR spectroscopy evidences that the aldehyde content decreases during the second reaction recorded in DSC. In addition, no weight loss is recorded within the same temperature range during curing (Fig. S10C), i.e. no condensation reaction occurs. Thus, the second reaction should involve the addition of phenolic free positions onto the second TPA aldehyde (reaction II in Scheme 2). Once most of the methylenol groups are reacted, the second aldehyde of TPA - being not anymore involved in resonance forms - will react with free phenol positions (consecutive reactions, shift from reaction I to II). Hence the condensation of the second methylenol group would not occur (not observed in DSC for phenol-, resorcinol- and guaiacol-TPA) because of (i) a lack of reactive phenolic position and (ii) a lack of resonance forms which would stabilize intermediates in reaction I (Schemes 2-3). By extension, similar mechanisms for resorcinol-, guaiacol- and tyrosol-TPA are expected due to comparable trends recorded in DSC curing. Moreover, for tyrosol the total enthalpy of reaction is very low compared to other phenols, indicating that fewer phenolic positions have reacted. Thus, the third reaction can be ascribed to the condensation of the second methylenol probably because of sufficient remaining reactive phenolic positions. It is verified that this enthalpy is not related to degradation: this exothermic peak vanishes after autoclave curing (two-steps isothermal program $100-200^{\circ} \mathrm{C}$, cf. Supporting Information). 


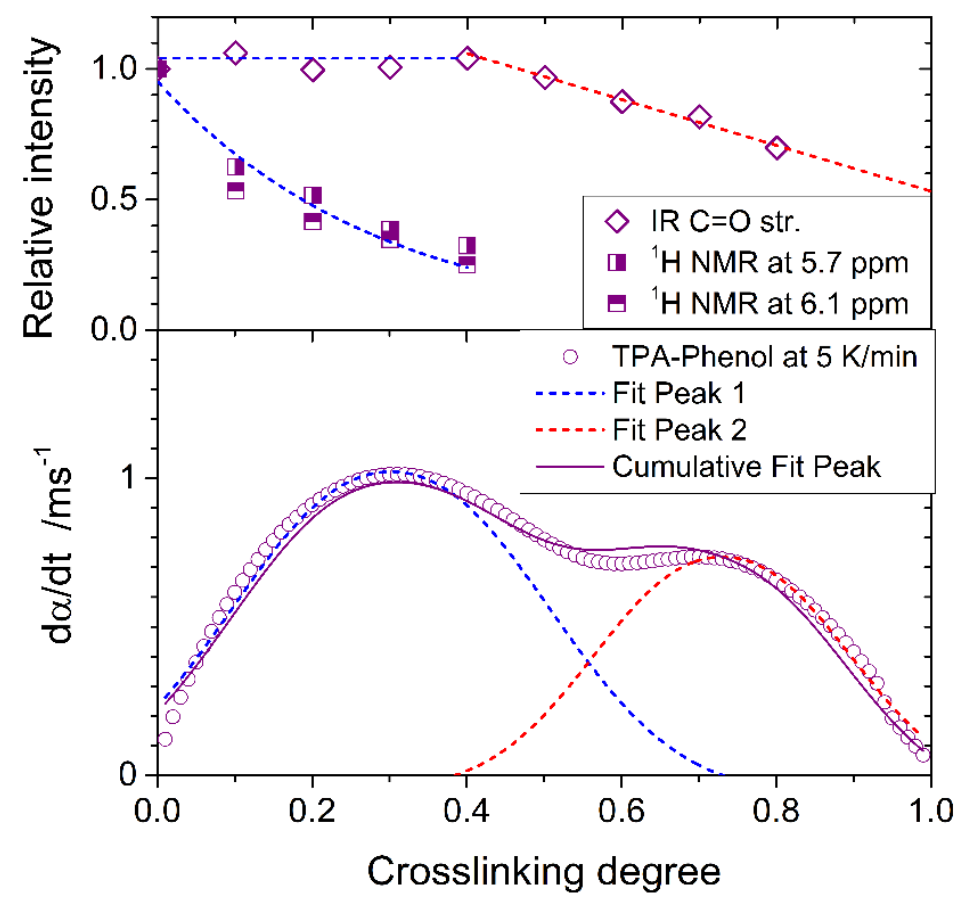

Fig. 2 Relative intensities ( $I=1$ for $\alpha=0$ ) of the band of aldehyde (IR) and methylenol (NMR), and reaction rate vs. crosslinking degree during DSC curing at $5{ }^{\circ} \mathrm{C} / \mathrm{min}$, with Gaussian functions deconvolution.

Pre-polymerization<smiles>[R]c1ccc(O)c(O)c1</smiles>

Reaction I<smiles>[R]c1ccc(C(O)c2ccc(C=O)cc2)cc1</smiles><smiles>CCP(CC)c1ccc(O)cc1</smiles><smiles>[R]c1ccc(C(c2ccccc2)c2ccc(O)cc2)cc1</smiles>

Reaction II<smiles>[R]c1ccc(O)c(C(c2ccc(O)cc2)c2ccc(C=O)cc2)c1</smiles>

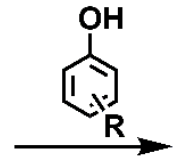<smiles>[R]c1ccc(C(c2ccc(C(O)c3cccc(O)c3)cc2)c2ccc(O)o2)cc1</smiles>

Scheme 2: Postulated polymerization mechanism between TPA and phenols.

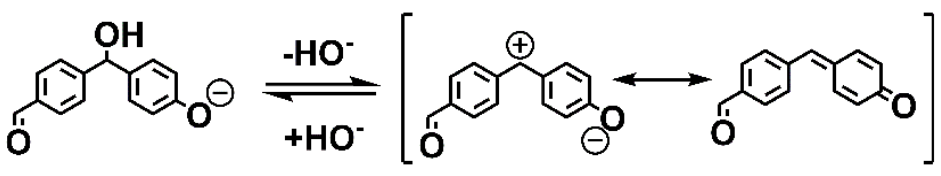

Scheme 3: Possible intermediate compounds in condensation reaction I between deprotonated phenol and TPA and resonance form examples.

\section{Crosslinking Kinetics}

The kinetic analysis gives further insights into the curing behavior of these formulations. A model-free kinetic method was performed on multiple heating rates integral DSC data (Fig. S9), using the advanced isoconversional method of Vyazovkin ${ }^{67}$. Basically, this kinetic analysis relies on the elucidation of the activation energy (rate constants described by Arrhenius equations). Theoretical and computation details of the implemented method are well-known ${ }^{68}$ and are 
therefore reported in the Supporting Information. The fundamental hypothesis of isoconversional methods states that the temperature program does not affect the reaction mechanisms. This assumption is easily verified from multiple linear heating rates data, with (i) a constant reaction enthalpy (Table S5), (ii) parallel kinetic profiles (Fig. S9) and (iii) shifts from one reaction to another occurring at the same conversion, independently on the heating rates (e.g. consecutive reactions). From DSC data, all formulations satisfy the isoconversional principle. However, tyrosol-TPA crosslinking kinetics - which exhibited low DSC signals resulting in crossing traces - will not be presented, here.

Activation energy is displayed as a function of the crosslinking degree in Fig. 3. For all formulations, the activation energy spans over a wide range of values, from ca. 50 to $95 \mathrm{~kJ} \cdot \mathrm{mol}^{-1}$. These scattered values are in agreement with literature data on previous phenolic networks. ${ }^{69-73}$ The activation energy of PF curing process rises from ca. 70 to 80 $\mathrm{kJ} \cdot \mathrm{mol}^{-1}$ with the crosslinking degree. For other formulations, the activation energy curves display more complex trends. The activation energy decreases with the crosslinking degree for phenol-TPA, whereas it tends to increase for resorcinoland guaiacol-TPA. The slight increase for PF is assigned to an increasing energy barrier due to viscosity increase throughout the curing process. Moreover, no change in reaction mechanisms is suggested for this formulation. On the other hand, the activation energies vary more sharply for other formulations. This is ascribed to the shift of reaction pathways. Hence, isoconversional analysis is able to discriminate the apparent activation energies of the two consecutive reactions, namely $E_{1}$ and $E_{2}$ (Table 1 ), sufficiently far from the shift zone from one reaction to another. The activation energy of the reaction I, $E_{1}$, varies significantly from one formulation to another. Energy $E_{1}$ of phenol-TPA which corresponds to the condensation of phenol onto methylenol groups - is remarkably similar to the activation energy of $78 \mathrm{~kJ} \cdot \mathrm{mol}^{-1}$ for phenol condensation on methylol for PF. Thus, the condensation mechanisms between phenol and TPA can be considered similar to those of phenol and formaldehyde. In contrast, the $+\mathrm{M}$ electron-donor substituents on resorcinol and guaiacol (phenoxide and methoxy, respectively) tend to lower the activation energy, $E_{1}=$ 55 and $64 \mathrm{~kJ} \cdot \mathrm{mol}^{-1}$, respectively. Hence, the more donor is the substituent, the lower is the activation energy. Indeed, the phenolic substituents - generating extra resonance forms - would stabilize the methide quinone intermediates (Scheme 3), which tends to lower the activation energy barrier. Further theoretical studies would be of a precious help in order to support these observations. The activation energy of the reaction II, $E_{2}$, for resorcinol is the lowest (near 62 $\left.\mathrm{kJ} \cdot \mathrm{mol}^{-1}\right)$. Again, this is explained by the enhanced reactivity of fully deprotonated resorcinol. On the other hand, the activation energy of aldehyde addition onto guaiacol is $91 \mathrm{~kJ} \cdot \mathrm{mol}^{-1}$, which is ca. $20 \mathrm{~kJ} \cdot \mathrm{mol}^{-1}$ higher than the addition onto phenol. The guaiacol phenolic positions may need to overcome a higher barrier than other phenols to diffuse to the TPA, because guaiacol has one less reactive position than phenol and the methoxy substituent may cause steric hindrance. In thermosetting curing, the diffusion contributions are particularly important toward the end of the curing process, during which the viscosity increases considerably ${ }^{74}$. Thus, a non-negligible contribution of the diffusion tends to increase the values of the apparent activation energy ${ }^{75}$, as was observed for the last stages of curing of the guaiacol-TPA resins.

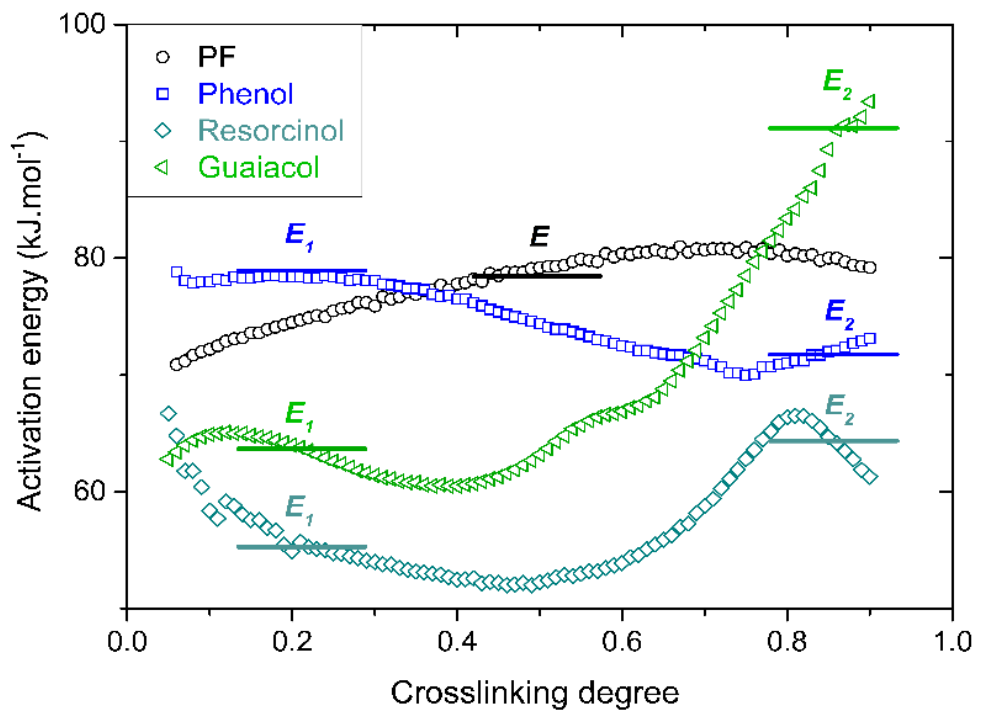

Fig. 3: Apparent activation energy throughout the crosslinking process. 
Hence, the curing analysis provided a better understanding of the mechanism underway during TPA based resoles crosslinking. Furthermore, the kinetics analysis is of precious help in the design of industrially applicable curing schemes. For instance, a two-step curing has been designed from multiple isothermal kinetic predictions (Fig. S11A). One slow pre-curing stage was performed out-of-autoclave at $100^{\circ} \mathrm{C}$, for 3 days, in order to get rid of the volatiles. Then, the samples were cured in autoclave at $200^{\circ} \mathrm{C}$, for 8 hours, under a pressure of 10 bar (nitrogen atmosphere), to achieve complete crosslinking. DSC analyses of the cured samples showed no residual enthalpy for all formulations. After final curing, the solid contents were satisfactory, and all samples were completely insoluble (Fig. S11C). The cured samples were under the form of hard brown-black monoliths, without any macro-porosity (Fig. S11B).

\section{Thermo-mechanical behaviors}

Dynamic mechanical analysis (DMA) was performed on the fully cured resoles (cf. Supporting Information for curing schemes and sample photography). The DMA traces near the glass transitions of resoles are displayed in Fig. 4. Both inflexion of Young's storage modulus, E', and damping peak are typical of glass transition of thermosetting networks. The materials devitrify, i.e. they pass from the glassy to the rubbery state, which corresponds to the cooperative relaxation of the polymer network. ${ }^{76,77}$ The storage modulus values at the glassy plateau, $\mathrm{E}_{\text {glass, }}$, relate to the rigidity of materials (Table 1). No strong variation is recorded, and the rigidities of the TPA-based resoles (ranging from 1.2 to $3.0 \mathrm{GPa}$ ) are comparable to the value of the commercial PF resole of this study and to literature values of phenolic networks. ${ }^{78,79}$ The value of the height of the rubbery plateau, $E_{r}^{\prime}$, is related to the crosslink density, as described by the rubber elasticity theory of Flory. ${ }^{80}$ Tyrosol-TPA presents a value of rubber plateau similar to PF ( $\left.E_{r}^{\prime} \sim 50 \mathrm{MPa}\right)$, which suggests that tyrosol-TPA is less densely crosslinked than its other TPA-based counterparts. This result is in accordance with the curing study, which recorded very low enthalpy of crosslinking in tyrosol-TPA. Among the studied resoles, phenol, resorcinol- and guaiacol-TPA exhibit a very dense crosslinking, with values of $\mathrm{E}_{r}^{\prime}$ ranging from 320 to $700 \mathrm{MPa}$. These values are very high compared to previous values of $\mathrm{PF}^{78,79}$ and other bio-based materials ${ }^{81,82}$ and are comparable to the very good results ${ }^{59}$ obtained by Zhao and Abu-Omar.

The values of the glass transition temperatures are readily estimated from the temperatures of the $\alpha$-transitions, at maximum of damping peak $\left(T_{\alpha}\right)$. DMA allows determining glass transition temperatures of the resoles, whereas DSC fails to measure it (no sharp heat capacity changes were recorded). Phenol-, resorcinol- and guaiacol-TPA resoles have similar $T_{\alpha}$ of $160-164{ }^{\circ} \mathrm{C}$. Interestingly, the $+\mathrm{M}$ electron-donor substituent (such as phenoxide and methoxy) has no impact on the glass transition temperature or the crosslink density. Although these values are lower than PF ones (196 $\left.{ }^{\circ} \mathrm{C}\right)$, they are still fairly elevated and thus well suited for high performance applications. Tyrosol-TPA resoles present a closer $T_{\alpha}$ value $\left(184{ }^{\circ} \mathrm{C}\right)$ than PF. The tyrosol-TPA $T_{\alpha}$ value is higher than that of other synthesized resoles. This may be attributed to the dangling ethanol moiety of tyrosol units that can be involved in hydrogen bonding. Thus, the glass transition temperature value of tyrosol-TPA spans over a wider temperature range, which may be the consequence of exchangeable hydrogen bondings. 

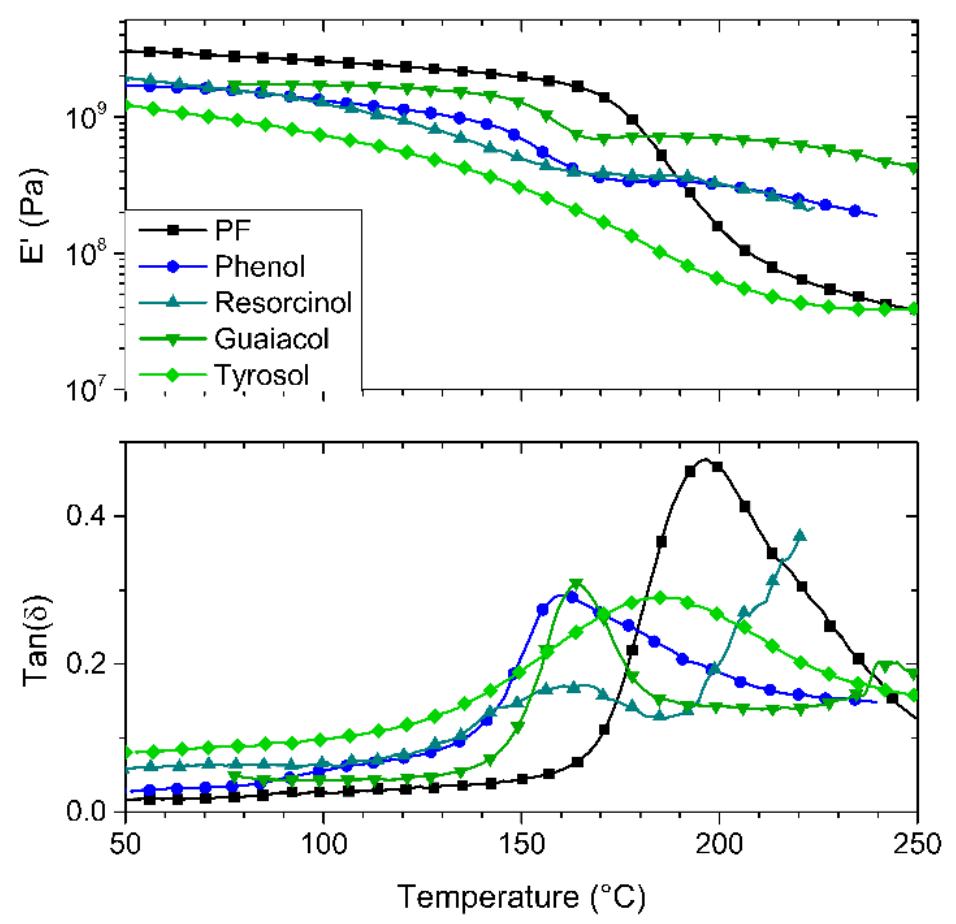

Fig. 4: DMA traces of the cured materials: storage modulus and loss tangent.

\section{Thermal performances}

The thermal performances under pyrolysis were evaluated using TGA. The experimental procedure is given in the Supporting Information. Superimposed TGA thermograms are displayed in Fig. 5A. Sigmoidal curves are observed, typical of resole pyrolysis. ${ }^{72}$ Each observed slope break relates a shift from one degradation mechanism to another. The temperatures of phenomena are better determined from peaks on differential curves (Fig. 5B). The first slight weight loss $\left(\sim 5\right.$ wt.\%, for $\mathrm{T}<300^{\circ} \mathrm{C}$ ) observed for PF, resorcinol- and tyrosol-TPA is attributed to volatile evaporation. ${ }^{83,84}$ The latter 2 comprise a larger amount of ethanol than the other formulations. The second weight loss occurring only for TPA resoles (about $10 \mathrm{wt} . \%, \mathrm{~T}<450{ }^{\circ} \mathrm{C}$ ) can be attributed to the oxidation of remaining methylenol groups and/or decarbonylation of dangling TPA aldehyde moiety. The crosslinks degradation occurs between 400 and $500{ }^{\circ} \mathrm{C}$ (about 10 wt.\%). Hence, this weight loss involves oxidation of methylene bridges for PF and oxidation of triphenylmethane moiety for TPA resoles (occurring at higher temperature). The last weight loss $\left(\sim 10-15 \mathrm{wt} . \%, 500<\mathrm{T}<600{ }^{\circ} \mathrm{C}\right)$ is assigned to ring dehydrogenation forming the amorphous residual char. ${ }^{83,84}$ The char residues are stable (curves level-off before 900 ${ }^{\circ} \mathrm{C}$ ). The temperatures at $10 \mathrm{wt} . \%$ of degradation and char yields are very high for all formulations (Table 1). Tyrosol-TPA shows the lowest thermal stability, which is expected according to its lower crosslink density. Resorcinol- and guaiacolTPA present similar thermal characteristic than commercial PF. Phenol-TPA formulation reaches the best performances. For future development of these biobased resoles, the stoichiometry should be optimized in order to achieve maximum thermal performances. Moreover, such thermal performances for biobased materials have been very rarely reported beforehand. The excellent thermal stability of these biobased networks is mainly due to high aromatic and crosslink densities. These very promising results show that they can seriously compete commercial formulation of PF resoles. 

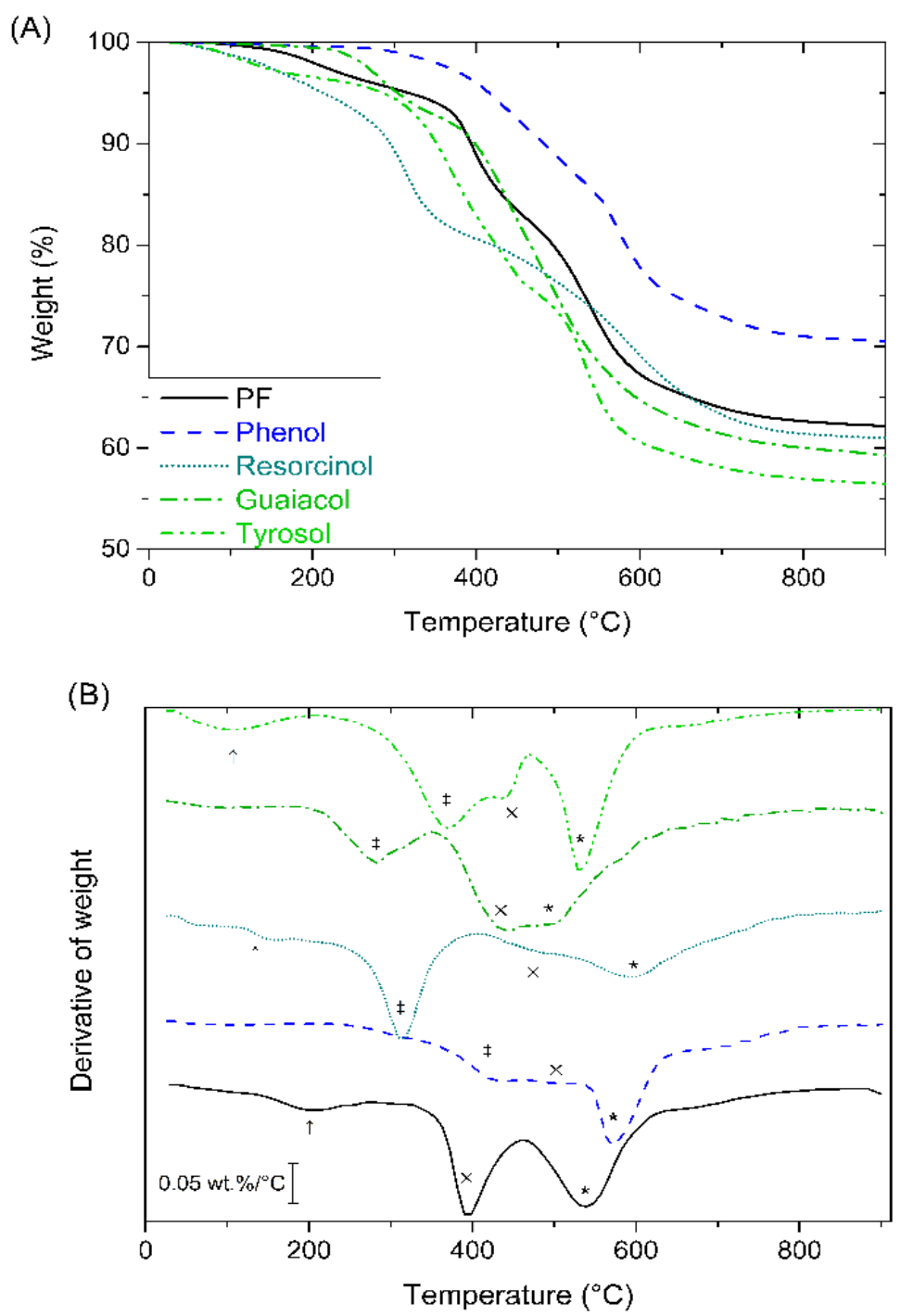

Fig. 5: (A) TGA thermograms of fully cured resoles, recorded at $10 \mathrm{~K} \cdot \mathrm{min}-1$ under nitrogen atmosphere. (B) derivative curves highlighting changes in degradation mechanisms, with according assignments: ( $\uparrow$ ) volatile evaporation, ( $¥)$ oxidation of methylenol group.

Table 1. Crosslinking activation energies, glass transition temperature, rigidity, rubbery plateau, temperature at 10 wt.\% degradation and char yields at $900^{\circ} \mathrm{C}$ under pyrolysis.

\begin{tabular}{lccccccc}
\hline \multicolumn{1}{c}{ Formulation } & $\begin{array}{c}E_{l} \\
\left(\mathrm{~kJ} \cdot \mathrm{mol}^{-1}\right)\end{array}$ & $\begin{array}{c}E_{2} \\
\left(\mathrm{~kJ} \cdot \mathrm{mol}^{-1}\right)\end{array}$ & $T_{\alpha}\left({ }^{\circ} \mathrm{C}\right)^{\mathrm{a}}$ & $\begin{array}{c}\text { Rigidity, } \\
\boldsymbol{E}_{\text {glass }}^{\prime} \\
(\mathrm{GPa})^{\mathrm{b}}\end{array}$ & $\begin{array}{c}\text { Rubbery } \\
\text { plateau, } \\
\boldsymbol{E}_{\boldsymbol{r}}^{\prime}(\mathrm{GPa})^{\mathrm{c}}\end{array}$ & $\begin{array}{c}T_{d 10 \%} \\
\left({ }^{\circ} \mathrm{C}\right)\end{array}$ & $\begin{array}{c}\text { Char } \\
\text { yields } \\
(\mathrm{wt} . \%)\end{array}$ \\
\hline $\begin{array}{l}\text { Phenol- } \\
\text { formaldehyde }\end{array}$ & 78 & - & 196 & 3.0 & 0.05 & 393 & $62 \pm 1$ \\
\hline Phenol-TPA & 78 & 72 & 160 & 1.7 & 0.32 & 485 & $71 \pm 1$ \\
\hline Resorcinol-TPA & 55 & 62 & 161 & 2.0 & 0.32 & 394 & $61 \pm 1$ \\
\hline Guaiacol-TPA & 64 & 91 & 164 & 1.7 & 0.70 & 345 & $59 \pm 1$ \\
\hline Tyrosol-TPA & - & - & 184 & 1.2 & 0.04 & 290 & $57 \pm 1$ \\
\hline
\end{tabular}

a Temperature of the $\alpha$-transition taken at the maximum of $\tan (\delta)$,

${ }^{b}$ height of the storage glassy plateau, at $50{ }^{\circ} \mathrm{C}$,

${ }^{\mathrm{c}}$ height of the storage rubbery plateau, at $T_{\alpha}+50^{\circ} \mathrm{C}$.

\section{Conclusions}

The main issue of thermally stable phenolic resins remain the high toxicity of precursors. In this paper, we demonstrated that non-toxic biobased building blocks could allow to overcome this issue. Terephthalaldehyde (TPA) was proven to be an aldehyde of prime choice to replace formaldehyde in resole formulation. Besides, several bio-based 
phenols (resorcinol, guaiacol and tyrosol) were successfully reacted with TPA. Solid materials and composites, as well as foams, can be readily formed under mild conditions and without any addition of further additives. This study provided interesting information on the reaction mechanisms of these new bio-based resoles, and especially on crosslinking mechanisms and kinetics, which were poorly known. With the generated data, one can design optimized curing schemes adapted to industrial processes. Interestingly we demonstrated that the resorcinol-TPA is a cold curable thermoset. In addition, we showed that very interesting chemical and physical properties were achieved with very few process and synthesis optimizations, and without any addition of network modifier. The networks displayed fairly high glass transition temperatures. More interestingly, dynamic mechanical analyses highlighted the extremely high crosslink density (for phenol-, resorcinol- and guaiacol-TPA). This suggests a possible enhanced resistance to solvent permeation, for example. From these findings, one can imagine that these more sustainable resoles could replace current highperformance resins. Furthermore, we proved that the synthetized biobased resoles can compete the phenolformaldehyde resoles in terms of thermal performances. High degradation temperatures and high char yields make them serious candidates for composite manufacturing in aerospace, such as ablative materials. Further investigations are ongoing to clarify the degradation mechanisms and flame retardance properties. Finally, the good availability of the building blocks and the processing simplicity, together with the outstanding properties of these biobased phenolic resins, are very encouraging in the course of replacing hazardous phenol and formaldehyde in high performances resole formulations currently used in mass production.

\section{Conflicts of interest}

There are no conflicts to declare.

\section{Acknowledgements}

The authors are grateful to the "Mesures Physiques" laboratory of the University of Montpellier for MALDI-ToF measurements.

\section{Notes and references}

(1) Hirano, K.; Asami, M. Phenolic Resins-100 Years of Progress and Their Future. Reactive and Functional Polymers. 2013, pp 256-269.

(2) Pilato, L. Phenolic Resins: 100Years and Still Going Strong. React. Funct. Polym. 2013, 73 (2), $270-277$.

(3) Pizzi, A.; Ibeh, C. C. Phenol-Formaldehydes. In Handbook of Thermoset Plastics; Elsevier, 2014; pp 13-44.

(4) Kotzebue, L. R. V.; De Oliveira, J. R.; Da Silva, J. B.; Mazzetto, S. E.; Ishida, H.; Lomonaco, D. Development of Fully Biobased HighPerformance Bis-Benzoxazine under Environmentally Friendly Conditions. ACS Sustain. Chem. Eng. 2018, 6 (4), 5485-5494.

(5) Wan, J.; Gan, B.; Li, C.; Molina-Aldareguia, J.; Kalali, E. N.; Wang, X.; Wang, D. Y. A Sustainable, Eugenol-Derived Epoxy Resin with High Biobased Content, Modulus, Hardness and Low Flammability: Synthesis, Curing Kinetics and Structure-Property Relationship. Chem. Eng. J. 2016, 284, 1080-1093.

(6) Gardziella, A.; Pilato, L. a.; Knop, A. Phenolic Resins: Chemistry, Applications, Standardization, Safety and Ecology; Springer Berlin Heidelberg: Berlin, Heidelberg, 2000.

(7) Natali, M.; Kenny, J. M.; Torre, L. Science and Technology of Polymeric Ablative Materials for Thermal Protection Systems and Propulsion Devices: A Review. Progress in Materials Science. 2016, pp 192-275.

(8) European Chemical Agency. Annex VI of Regulation (EC) No 1272/2008 (CLP Regulation); 2015

(9) Briou, B.; Caillol, S.; Robin, J. J.; Lapinte, V. Cardanol-Based and Formaldehyde-Free Flexible Phenolic Networks. Eur. J. Lipid Sci. Technol. 2018, 120 (7), 1800175.

(10) Ballerini, A.; Despres, A.; Pizzi, A. Non-Toxic, Zero Emission Tannin-Glyoxal Adhesives for Wood Panels. Holz als Roh- und Werkst. 2005, 63 (6), 477-478.

(11) Brown, L. H. Resin Forming Reactions of Furfural and Phenol. Ind. Eng. Chem. 1952, 44 (11), 2673-2675.

(12) Pizzi, A.; Orovan, E.; Cameron, F. A. The Development of Weather- and Boil-Proof Phenol-Resorcinol-Furfural Cold-Setting Adhesives. Holz als Roh- und Werkst. 1984, 42 (12), 467-472.

(13) Foyer, G.; Chanfi, B. H.; Virieux, D.; David, G.; Caillol, S. Aromatic Dialdehyde Precursors from Lignin Derivatives for the Synthesis of Formaldehyde-Free and High Char Yield Phenolic Resins. Eur. Polym. J. 2016, 77, 65-74.

(14) Boukis, A. C.; Llevot, A.; Meier, M. A. R. High Glass Transition Temperature Renewable Polymers via Biginelli Multicomponent Polymerization. Macromol. Rapid Commun. 2016, 37 (7), 643-649.

(15) Brindell, G. D.; Lillwitz, L. D.; Wuskell, J. P.; Dunlop, A. P. Polymer Applications of Some Terephthalaldehyde Derivatives. Ind. Eng. Chem. Prod. Res. Dev. 1976, 15 (1), 83-88.

(16) Qin, Z. zeng; Su, T. ming; Jiang, Y. xiu; Ji, H. bing; Qin, W. guo. Preparation of W-Modified FeMo Catalyst and Its Applications in the Selective Oxidization of p-Xylene to Terephthalaldehyde. Chem. Eng. J. 2014, 242, 414-421.

(17) Mathers, R. T. How Well Can Renewable Resources Mimic Commodity Monomers and Polymers? J. Polym. Sci. Part A Polym. Chem. 2012, 50 (1), 1-15.

(18) Peters, M. W.; Taylor, J. D.; Jenni, M.; Manzer, L. E.; Henton, D. E. Integrated Process to Selectively Convert Renewable Isobutanol to PXylene, 2011. 
(19) Settle, A. E.; Berstis, L.; Rorrer, N. A.; Roman-Leshkóv, Y.; Beckham, G. T.; Richards, R. M.; Vardon, D. R. Heterogeneous Diels-Alder Catalysis for Biomass-Derived Aromatic Compounds. Green Chem. 2017, 19 (15), 3468-3492.

(20) Maneffa, A.; Priecel, P.; Lopez-Sanchez, J. A. Biomass-Derived Renewable Aromatics: Selective Routes and Outlook for $p$-Xylene Commercialisation. ChemSusChem 2016, 9 (19), 2736-2748.

(21) Granado, L.; Tavernier, R.; Foyer, G.; David, G.; Caillol, S. Comparative Curing Kinetics Study of High Char Yield Formaldehyde- and Terephthalaldehyde-Phenolic Thermosets. Thermochim. Acta 2018.

(22) Lochab, B.; Shukla, S.; Varma, I. K. Naturally Occurring Phenolic Sources: Monomers and Polymers. RSC Advances. 2014, p 21712.

(23) Schutyser, W.; Renders, T.; Van Den Bosch, S.; Koelewijn, S. F.; Beckham, G. T.; Sels, B. F. Chemicals from Lignin: An Interplay of Lignocellulose Fractionation, Depolymerisation, and Upgrading. Chem. Soc. Rev. 2018, 47 (3), 852-908.

(24) Kai, D.; Tan, M. J.; Chee, P. L.; Chua, Y. K.; Yap, Y. L.; Loh, X. J. Towards Lignin-Based Functional Materials in a Sustainable World. Green Chem. 2016, 18 (5), 1175-1200.

(25) Matsushita, Y.; Hirano, D.; Aoki, D.; Yagami, S.; Takagi, Y.; Fukushima, K. A Biobased Flame-Retardant Resin Based on Lignin. Adv. Sustain. Syst. 2017, 1 (10), 1700073.

(26) Gillet, S.; Aguedo, M.; Petitjean, L.; Morais, A. R. C.; Da Costa Lopes, A. M.; Łukasik, R. M.; Anastas, P. T. Lignin Transformations for High Value Applications: Towards Targeted Modifications Using Green Chemistry. Green Chem. 2017, 19 (18), $4200-4233$.

(27) Chatterjee, S.; Saito, T. Lignin-Derived Advanced Carbon Materials. ChemSusChem 2015, 8 (23), 3941-3958.

(28) Tejado, A.; Peña, C.; Labidi, J.; Echeverria, J. M.; Mondragon, I. Physico-Chemical Characterization of Lignins from Different Sources for Use in Phenol-Formaldehyde Resin Synthesis. Bioresour. Technol. 2007, 98 (8), 1655-1663.

(29) Tejado, A.; Kortaberria, G.; Labidi, J.; Echeverria, J. M.; Mondragon, I. Isoconversional Kinetic Analysis of Novolac-Type Lignophenolic Resins Cure. Thermochim. Acta 2008, 471 (1-2), 80-85.

(30) Siddiqui, H.; Mahmood, N.; Yuan, Z.; Crapulli, F.; Dessbesell, L.; Rizkalla, A.; Ray, A.; Xu, C. Sustainable Bio-Based Phenol-Formaldehyde Resoles Using Hydrolytically Depolymerized Kraft Lignin. Molecules 2017, 22 (11).

(31) Stanzione, J. F.; Sadler, J. M.; La Scala, J. J.; Wool, R. P. Lignin Model Compounds as Bio-Based Reactive Diluents for Liquid Molding Resins. ChemSusChem 2012, 5 (7), 1291-1297.

(32) Li, J.; Zhang, J.; Zhang, S.; Gao, Q.; Li, J.; Zhang, W. Fast Curing Bio-Based Phenolic Resins via Lignin Demethylated under Mild Reaction Condition. Polymers (Basel). 2017, 9 (9).

(33) Li, J.; Wang, W.; Zhang, S.; Gao, Q.; Zhang, W.; Li, J. Preparation and Characterization of Lignin Demethylated at Atmospheric Pressure and Its Application in Fast Curing Biobased Phenolic Resins. RSC Adv. 2016, 6 (71), 67435-67443.

(34) Pratihar, S.; Roy, S. Nucleophilicity and Site Selectivity of Commonly Used Arenes and Heteroarenes. J. Org. Chem. 2010, 75 (15), 49574963.

(35) Periyasamy, T.; Asrafali, S. P.; Muthusamy, S.; Kim, S. C. Replacing Bisphenol-A with Bisguaiacol-F to Synthesize Polybenzoxazines for a Pollution-Free Environment. New J. Chem. 2016, 40 (11), 9313-9319.

(36) Bu, Q.; Lei, H.; Wang, L.; Wei, Y.; Zhu, L.; Zhang, X.; Liu, Y.; Yadavalli, G.; Tang, J. Bio-Based Phenols and Fuel Production from Catalytic Microwave Pyrolysis of Lignin by Activated Carbons. Bioresour. Technol. 2014, 162, 142-147.

(37) Rinaldi, R.; Jastrzebski, R.; Clough, M. T.; Ralph, J.; Kennema, M.; Bruijnincx, P. C. A.; Weckhuysen, B. M. Paving the Way for Lignin Valorisation: Recent Advances in Bioengineering, Biorefining and Catalysis. Angew. Chemie Int. Ed. 2016, 55 (29), 8164-8215.

(38) Pizzi, A.; Mtsweni, B.; Parsons, W. Wood-induced Catalytic Activation of PF Adhesives Autopolymerization vs. PF/Wood Covalent Bonding. J. Appl. Polym. Sci. 1994, 52 (13), 1847-1856.

(39) Lindberg, J. J.; Erä, V. A.; Sairanen, H. Novolak Resins from Phenol and Guaiacol. Die Angew. Makromol. Chemie 1974, 39 (1), $159-165$.

(40) Curia, S.; Biundo, A.; Fischer, I.; Braunschmid, V.; Gübitz, G. M.; Stanzione, J. F. Towards Sustainable High-Performance Thermoplastics: Synthesis, Characterization, and Enzymatic Hydrolysis of Bisguaiacol-Based Polyesters. ChemSusChem 2018, 11 (15), $2529-2539$.

(41) Arbenz, A.; Avérous, L. Chemical Modification of Tannins to Elaborate Aromatic Biobased Macromolecular Architectures. Green Chem. 2015, 17 (5), 2626-2646.

(42) Pizzi, A.; Horak, R. M.; Ferreira, D.; Roux, D. G. Condensates of Phenol, Resorcinol, Phloroglucinol, and Pyrogallol as Model Compounds of Flavonoid A- and B-rings with Formaldehyde. Journal of Applied Polymer Science. 1979, pp 1571-1578.

(43) Van Gils, G. E. Reaction of Resorcinol and Formaldehyde in Latex Adhesives for Tire Cords. Ind. Eng. Chem. Prod. Res. Dev. 1968, 7 (2), 151154.

(44) Pizzi, A.; Scharfetter, H. O. The Chemistry and Development of Tannin-Based Adhesives for Exterior Plywood. J. Appl. Polym. Sci. 1978, 22 (6), 1745-1761.

(45) Badhe, Y.; Balasubramanian, K. Novel Hybrid Ablative Composites of Resorcinol Formaldehyde as Thermal Protection Systems for Re-Entry Vehicles. RSC Adv. 2014, 4 (55), 28956-28963.

(46) Durairaj, R. B. Resorcinol: Chemistry, Techonoly and Applications; Springer: Berlin/Heidelberg, 2005.

(47) Gioia, C.; Banella, M. B.; Vannini, M.; Celli, A.; Colonna, M.; Caretti, D. Resorcinol: A Potentially Bio-Based Building Block for the Preparation of Sustainable Polyesters. Eur. Polym. J. 2015, 73, 38-49.

(48) Frost, J. W. Environmentally Benign Synthesis of Resorcinol from Glucose, EPA Final Report.

(49) Charrouf, Z.; Guillaume, D. Argan Oil: Occurrence, Composition and Impact on Human Health. European Journal of Lipid Science and Technology. July 2008, pp 632-636.

(50) Larriba, M.; Omar, S.; Navarro, P.; García, J.; Rodríguez, F.; Gonzalez-Miquel, M. Recovery of Tyrosol from Aqueous Streams Using Hydrophobic lonic Liquids: A First Step towards Developing Sustainable Processes for Olive Mill Wastewater (OMW) Management. RSC Adv. 2016, 6 (23), 18751-18762.

(51) Ciriminna, R.; Meneguzzo, F.; Delisi, R.; Pagliaro, M. Olive Biophenols as New Antioxidant Additives in Food and Beverage. ChemistrySelect 2017, 2 (4), 1360-1365.

(52) European Commission Directorate-General for Agriculture and Rural Development. Economic Analysis of the Olive Sector; 2012.

(53) Kalogerakis, N.; Politi, M.; Foteinis, S.; Chatzisymeon, E.; Mantzavinos, D. Recovery of Antioxidants from Olive Mill Wastewaters: A Viable Solution That Promotes Their Overall Sustainable Management. J. Environ. Manage. 2013, 128, 749-758. 
(54) Reis, M. T. A.; de Freitas, O. M. F.; Ferreira, L. M.; Carvalho, J. M. R. Extraction of 2-(4-Hydroxyphenyl)Ethanol from Aqueous Solution by Emulsion Liquid Membranes. J. Memb. Sci. 2006, 269 (1-2), 161-170.

(55) Satoh, Y.; Tajima, K.; Munekata, M.; Keasling, J. D.; Lee, T. S. Engineering of a Tyrosol-Producing Pathway, Utilizing Simple Sugar and the Central Metabolic Tyrosine, in Escherichia Coli. J. Agric. Food Chem. 2012, 60 (4), 979-984.

(56) Bouldin, R. M.; Xia, Z.; Klement, T. J.; Kiratitanavit, W.; Nagarajan, R. Bioinspired Flame Retardant Polymers of Tyrosol. J. Appl. Polym. Sci. 2017, 134 (41), 1-7.

(57) Diao, L.; Wan, P. Chemistry of Photogenerated $\alpha$-Phenyl-Substituted $o-, m-$, and $p$-Quinone Methides from Phenol Derivatives in Aqueous Solution. Can. J. Chem. 2008, 86 (2), 105-118.

(58) Forest, K.; Wan, P.; Preston, C. M. Catechin and Hydroxybenzhydrols as Models for the Environmental Photochemistry of Tannins and Lignins. Photochem. Photobiol. Sci. 2004, 3 (5), 463-472.

(59) Zhao, S.; Abu-Omar, M. M. Renewable Thermoplastics Based on Lignin-Derived Polyphenols. Macromolecules 2017,50 (9), $3573-3581$.

(60) Pizzi, A.; Pasch, H.; Simon, C.; Rode, K. Structure of Resorcinol, Phenol, and Furan Resins by MALDI-TOF Mass Spectrometry And13C NMR. J. Appl. Polym. Sci. 2004, 92 (4), 2665-2674.

(61) Higuchi, M.; Yoshimatsu, T.; Urakawa, T.; Morita, M. Kinetics and Mechanisms of the Condensation Reactions of Phenolic Resins II. BaseCatalyzed Self-Condensation of 4-Hydroxymethylphenol. Polym. J. 2001, 33 (10), 799.

(62) Singh, M. S.; Nagaraju, A.; Anand, N.; Chowdhury, S. Ortho-Quinone Methide (o-QM): A Highly Reactive, Ephemeral and Versatile Intermediate in Organic Synthesis. RSC Adv. 2014, 4 (99), 55924-55959.

(63) Lenghaus, K.; Qiao, G. G.; Solomon, D. H. Model Studies of the Curing of Resole Phenol-Formaldehyde Resins Part 1. The Behaviour of Ortho Quinone Methide in a Curing Resin. Polymer (Guildf). 2000, 41 (6), 1973-1979.

(64) Peter, M. G. Chemical Modifications of Biopolymers by Quinones and Quinone Methides. Angew. Chemie Int. Ed. English 1989, 28 (5), 555570.

(65) Van de Water, R. W.; Pettus, T. R. R. O-Quinone Methides: Intermediates Underdeveloped and Underutilized in Organic Synthesis. Tetrahedron 2002, 58 (27), 5367-5405.

(66) Diao, L.; Yang, C.; Wan, P. Quinone Methide Intermediates from the Photolysis of Hydroxybenzyl Alcohols in Aqueous Solution. J. Am. Chem. Soc. 1995, 117 (19), 5369-5370.

(67) Vyazovkin, S.; Dollimore, D. Linear and Nonlinear Procedures in Isoconversional Computations of the Activation Energy of Nonisothermal Reactions in Solids. J. Chem. Inf. Model. 1996, 36 (1), 42-45.

(68) Vyazovkin, S.; Burnham, A. K.; Criado, J. M.; Pérez-Maqueda, L. a.; Popescu, C.; Sbirrazzuoli, N. ICTAC Kinetics Committee Recommendations for Performing Kinetic Computations on Thermal Analysis Data. Thermochim. Acta 2011, 520 (1-2), 1-19.

(69) Gabilondo, N.; López, M.; Ramos, J. A.; Echeverría, J. M.; Mondragon, I. Curing Kinetics of Amine and Sodium Hydroxide Catalyzed PhenolFormaldehyde Resins. Journal of Thermal Analysis and Calorimetry. 2007, pp 229-236.

(70) Wang, J.; Laborie, M. P. G.; Wolcott, M. P. Comparison of Model-Free Kinetic Methods for Modeling the Cure Kinetics of Commercial Phenol-Formaldehyde Resins. Thermochim. Acta 2005, 439 (1-2), 68-73.

(71) He, G.; Riedl, B.; Aït-Kadi, A. Curing Process of Powdered Phenol-Formaldehyde Resol Resins and the Role of Water in the Curing Systems. Journal of Applied Polymer Science. 2003, pp 1371-1378.

(72) Lei, Y.; Wu, Q. Cure Kinetics of Aqueous Phenol-Formaldehyde Resins Used for Oriented Strandboard Manufacturing: Effect of Wood Flour. J. Appl. Polym. Sci. 2006, 102 (4), 3774-3781.

(73) Rivero, G.; Pettarin, V.; Vázquez, A.; Manfredi, L. B. Curing Kinetics of a Furan Resin and Its Nanocomposites. Thermochim. Acta 2011, 516 (1-2), 79-87.

(74) Corezzi, S.; Fioretto, D.; Santucci, G.; Kenny, J. M. Modeling Diffusion-Control in the Cure Kinetics of Epoxy-Amine Thermoset Resins: An Approach Based on Configurational Entropy. Polymer (Guildf). 2010, 51 (24), 5833-5845.

(75) Granado, L.; Kempa, S.; Gregoriades, L. J.; Brüning, F.; Genix, A.-C.; Fréty, N.; Anglaret, E. Kinetic Regimes in the Curing Process of EpoxyPhenol Composites. Thermochim. Acta 2018, 667, 185-192.

(76) Owen, A. J.; Bonart, R. Cooperative Relaxation Processes in Polymers. Polymer (Guildf). 1985, 26 (7), $1034-1038$.

(77) Matsuoka, S.; Hale, A. Cooperative Relaxation Processes in Polymers. J. Appl. Polym. Sci. 1997, 64 (1), 77-93.

(78) Manfredi, L. B.; De La Osa, O.; Galego Fernández, N.; Vázquez, A. Structure-Properties Relationship for Resols with Different Formaldehyde/Phenol Molar Ratio. Polymer (Guildf). 1999, 40 (13), 3867-3875.

(79) Follensbee, R. A.; Koutsky, J. A.; Christiansen, A. W.; Myers, G. E.; Geimer, R. L. Development of Dynamic Mechanical Methods to Characterize the Cure State of Phenolic Resole Resins. J. Appl. Polym. Sci. 1993, 47 (8), 1481-1496.

(80) Paul J. Flory. Principles of Polymer Chemistry; 1953.

(81) Shibata, M.; Ohkita, T. Fully Biobased Epoxy Resin Systems Composed of a Vanillin-Derived Epoxy Resin and Renewable Phenolic Hardeners. Eur. Polym. J. 2017, 92 (May), 165-173.

(82) Faye, I.; Decostanzi, M.; Ecochard, Y.; Caillol, S. Eugenol Bio-Based Epoxy Thermosets: From Clove to Applied Materials. Green Chem. 2017.

(83) Jackson, W. M.; Conley, R. T. High Temperature Oxidative Degradation of Phenol-formaldehyde Polycondensates. J. Appl. Polym. Sci. 1964, $8(5), 2163-2193$.

(84) Jiang, H.; Wang, J.; Wu, S.; Yuan, Z.; Hu, Z.; Wu, R.; Liu, Q. The Pyrolysis Mechanism of Phenol Formaldehyde Resin. Polym. Degrad. Stab. 2012, 97 (8), 1527-1533. 